\title{
The Relationship between Brand Authenticity, Brand Equity and Customer Satisfaction
}

\author{
Van Dat TRAN*, Thi Ngoc Linh VO**, Thu Quynh DINH*** \\ Received: February 18, 2020 Revised: March 1, 2020 Accepted: March 6, 2020.
}

\begin{abstract}
This study examines the relationship between brand authenticity, brand equity, and customer satisfaction. A total of 263 participants participated in this study. Participants rated a set of three brands: Apple, Starbuck, and Nike. Each participant rated the extent to which the items described his or her authenticity with the brands listed, the equity of the brands listed, and feelings of satisfaction toward the brands. This study employs confirmatory factor analysis and structural equation modeling. The results indicate that 1) brand authenticity positively relates to brand equity, and 2) brand authenticity effects to customer satisfaction. The findings suggest that marketers can use the brand authenticity for assessment, planning, and tracking purposes to understand the authenticity of their brands for their customers. Products of authenticity brand are better liked, viewed as higher quality, offer greater value and are more likely to be purchased than less authenticity brand. They can command a significant price premium. The findings provide useful support and evidence for brand management, as well as companies in other developing countries, to engage more in brand practices as a core element of their strategic and brand management. This means that managers should work to increase perceptions of authenticity for their offerings.
\end{abstract}

Keywords : Brand Authenticity, Brand Equity, Customer Satisfaction, Vietnam

JEL Classification Code : M30, M31, M37

\section{Introduction}

Authenticity is a concept of increasing importance to marketing. The roots of the construct are found in existential philosophy. From that base, authenticity has become important in psychoanalysis, semiotics, aesthetics, music, tourism, and the marketing and branding literature. Moreover, an increasing number of consumers today are asking for authentic products and services and are shunning

*First Author and Corresponding Author. Lecturer, Faculty of Business Administration, Banking University, Ho Chi Minh City, Vietnam [Postal Address: No. 36, Ton That Dam Street, Nguyen Thai Binh Ward, District 1, Ho Chi Minh City, 700000, Vietnam].

Email: dattv@buh.edu.vn

**Lecturer, Faculty of Business Administration, Banking University, Ho Chi Minh City, Vietnam. Email: linhvtn@buh.edu.vn

***Lecturer, Faculty of Business Administration, Banking University, Ho Chi Minh City, Vietnam. Email: quynhdt@buh.edu.vn

(c) Copyright: The Author(s)

This is an Open Access article distributed under the terms of the Creative Commons Attribution Non-Commercial License (http://Creativecommons.org/licenses/by-nc/4.0/) which permits unrestricted noncommercial use, distribution, and reproduction in any medium, provided the unrestricted noncommercial
original work is properly cited. fake and artificial ones (Gilmore \& Pine, 2007). Observing this need on the part of consumers, some marketers have begun to use authenticity as a brand-positioning strategy and a product appeal (Grayson \& Martinec, 2004). These studies show that authenticity is an important topic in both practical and academic areas. With regard to music, I found it especially interesting that authenticity in one genre can mean something completely different than authenticity in another genre. Once again, this phenomenon of authenticity has already been addressed within the academic literature surrounding music and performance.

Rose and Wood (2005) note that much may be gleaned by better understanding how "personal predilections" shape the way authenticity is constructed. Additionally, some authors suggest a positive connection between customer satisfaction and brand equity (Aaker, 1992; Anderson \& Sullivan, 1993; Blackston, 2000; Keller, 1993). According to Ailawadi, Lehmann, and Neslin (2003) customer satisfaction may influence brand equity through one direct and one indirect channel. This study investigate how customer feels and what they find authenticity about the 
brand. In particular, I agree that brand authenticity impact on satisfaction through brand equity.

The paper proposes and tests an integrative model of brand authenticity, brand equity and customer satisfaction. The results of this paper show that the mediating effect of experience value and satisfaction between service quality, and behavioral intentions. This study contributes to the branding literature by investigating brand authenticity, brand equity, and customer satisfaction.

The structure of this paper is as follows. Section 2 presents the theoretical background and a review of previous studies. Section 3 discusses the data and methodology. Section 4 summarizes the empirical results. Section 5 offers a discussion of results. The article ends with the sections outlining the conclusion and research limitations.

\section{Literature Review}

\subsection{Brand Authenticity}

Beverland and Farrelly (2010) identified that, when consumers have different goals, they seek authenticity in different kinds of experiences. Three broad goals are identified (control, connection, and virtue) that drive the systematic selection and evaluation of different consumption experiences as being inauthentic. Tran and Keng (2018) used qualitative and empirical methods to identify the six key dimensions of brand authenticity and develop a brand authenticity scale. As a result, a six-dimensional scale containing seventeen items was developed representing distinctive dimensions of brand authenticity: virtue, connection, realism, aesthetics, control, and originality. Finally, authenticity is an important part of building and maintaining a successful brand because it forms a unique brand identity (Beverland 2005) and provided a strong, favorable association (Keller, 1993).

In another study, Holt (2002) comes close to exploring the aesthetic properties of authenticity by examining the role of products, services, or performances which display some aspect of disinterest, lack of inherent economic agenda, or motivation for personal gain. This is similar to the idea of authenticity found in a study on the music industry where authenticity is focused on an aesthetic or imaginary experience that is continually negotiated in an ongoing interplay between performers, diverse commercial interests, fans, and the evolving image. Illustrative of this is Hughes (2000) definition that it is not simply an imitation, but is a sincere, real, true and original expression of its creator, and is a believable or credible representation or example of what it appears to be.

\subsection{Brand Equity}

Brand equity is regarded as a very important concept in business practice as well as in academic research because marketers can gain a competitive advantage through successful brands (Lassar, Mittal, \& Sharma, 1995). Brand equity has been viewed from both marketing and financial perspectives. In the context of marketing decision making, the former focuses on the aim of improving the efficiency of the marketing process. Two main frameworks conceptualize brand equity. Keller's (1993) conceptualization focuses on brand knowledge and involves two components: brand awareness and brand image. Ha (2018) showed that strong and effective online brand communities generate value creation practices, and value creation practices enhance brand loyalty. The mediating effects of community loyalty between value creation practices and brand loyalty were revealed. Bae, Kim, and Oh (2019) brand value factors influence purchase intention through brand loyalty, and it was found that brand loyalty is an important factor for oriental medicine cosmetics consumers, however mediator effects did not appear for brand satisfaction.

By contrast, Aaker (1991) provided one of the most generally accepted and comprehensive definitions of brand equity: "A set of brand assets and liabilities linked to a brand, its name, and symbol that add to or subtract from the value provided by a product or service to a firm and/or to that firm's customers." Yoo and Donthu (2001) developed a psychologically sound and cross-culturally generalizable measure of brand equity by testing Aaker's (1991) and Keller's (1993) conceptualizations. The author's etic measure of multidimensional brand equity (MBE) comprises 10 items representing the three dimensions of brand loyalty, and brand awareness/associations. Aaker (1991) defined brand loyalty as "the attachment that a customer has to a brand." In our study, brand loyalty refers to the tendency to be loyal to a focal brand, which is demonstrated by the intention to buy the brand as a primary choice (Oliver, 1997). To develop its questionnaire, the current study used the brand equity dimension of Yoo and Donthu (2001).

\subsection{Satisfaction}

Consumer always seeks a product, which can offer functional, symbolic, emotional, epistemic and situational benefits to them leading to satisfaction of their needs and wants. In today's world of a competitive market, there could be a variety of factors that influence the selection and purchase of any product or a brand. Satisfaction is often used as a predictor of future consumer purchases (Kasper, 1988). Customer satisfaction is considered to be a key element for a company's success in the market; a leading criterion in determining the quality of service or product to the customers; and it is also crucial for organizational survival. Moreover, it is known that one of the goals of corporate culture is to retain and satisfy both the current and past customers.

Oliver (1997) defined customer dissatisfaction as "the summary psychological state resulting when the emotion surrounding disconfirmed expectations is coupled with a consumer's prior feelings about the consumer experience." 
Customer satisfaction can be seen as a fulfillment of consumers' consumption goals as experienced and described by consumers. Satisfaction is consumers' judgment that a product or service feature, or the product or service itself, provided (or is providing) a pleasurable level of consumption-related fulfillment, including levels of underor over-fulfillment" (Oliver, 1997). Choi, Wang- and Chen (2019) finds the positive effects of information variety on information benefits, those of various communications on social benefits, and also positive roles of no limitation in expressing self to brand-related self-expression motivation. A review of 50 empirical studies on customer satisfaction showed that the antecedents to satisfaction varied between studies (Szymanski \& Henard, 2001). Usually, expectations, disconfirmation of expectations, performance, affect, and equity was used to model buyers' level of satisfaction. Since store image is usually measured as store performance, it was natural to choose performance in this study as well. To develop its questionnaire, the current study used five satisfaction items of Oliver (1997).

\subsection{Hypothesis}

In the following section, we discuss the relationship between brand authenticity, brand equity, and satisfaction. According to Kim, Kim, and An (2003) suggested that corporate-level brand and product-level brand, which constitutes an overall brand name, play a major role in influencing a potential recruit to pursue a job. Moreover, these observations about increasing sales and consumer loyalty by managing brand experience as parts of brand equity are mentioned in other literature (Aaker, 1991). Therefore, while people are consuming the product, they get the brand experience and brand authenticity, and then respond to brand equity, which they help generate by their repurchasing behavior. In addition, recognizing the importance of perceptions of authenticity, brand managers have often responded by imbuing their brands with indications of authenticity (Beverland \& Luxton, 2005). Therefore, this study infers the following hypothesis:

Hypothesis 1: Brand authenticity positively relates to brand equity

Brand authenticity should affect not only past-directed satisfaction judgments, but also future-directed consumer loyalty. Consumers should be more likely to buy a brand again and recommend it to others and less likely to buy an alternative brand (Mittal \& Kamakura, 2001; Oliver, 1997). Sheldon, Ryan, and Reis (1997) found a substantial correlation between the constructs of authenticity, satisfaction, and well-being. Moreover, McShane and Cunningham (2012) found that perceived authenticity can lead to positive outcomes such as organizational identification and employee connections.
Hypothesis 2: Brand authenticity positively relates to customer satisfaction

Some authors suggest a positive connection between customer satisfaction and brand equity (Aaker, 1992; Anderson \& Sullivan, 1993; Blackston, 2000; Keller, 1993). Companies consider improved customer satisfaction as being a principal strategy for gaining loyalty, improving willingness to pay, and enhancing the lifetime value of the customer to the firm (Keller \& Lehmann, 2006; Hogan, Lemon, \& Rust, 2002). According to Ailawadi et al. (2003), customer satisfaction may influence brand equity through one direct and one indirect channel. Remarkably, brand equity measures can include customer mind-set, as well as product market and financial market outputs related to brand In addition, Pappu and Quester (2006) demonstrated empirically a positive relationship between customer satisfaction and an intangible asset such as retailer equity. Torres and Tribó (2011) find that customer satisfaction has a positive direct effect on brand equity but an indirect negative one, through reductions in ownership concentration. Therefore, the third hypothesis 3 is suggested as follows:

Hypothesis 3: Brand equity positively relates to customer satisfaction.

\section{Research Method}

\subsection{Research Design}

To measure these objectives, empirical data had to be collected and later be used for analyzing and finding the results. In order to gather the empirical data, a questionnaire had to be designed as explained in detail in the next stage.

The first stage involved a review of the literature and feedback from experts in the area of interest to obtain information and find out how other researchers previously did their studies. Then, empirical data was collected from customers to achieve the research objectives of this study. Based on the research objectives, a sample questionnaire mainly with a 7-point Likert type scale and an open-ended question was initially developed and pre-tested on a small sample of customer to ensure the quality of the questionnaire that the questions were not misleading or confusing in order to avoid any biases of the answers. After revision, a final questionnaire was developed to collect the data for which variables were incorporated.

\subsection{Measurement}

A total of 263 students participated in this study. Participants rated a set of three brands for three versions: Apple, Starbuck and Nike. Each participant rated the extent to which the items described his or her authenticity with the 
brands listed, the equity of the brands listed, and feelings of satisfaction toward the brands. The main objective of this research is to find out the factors affecting customer satisfaction. For achieving these research objectives, we have chosen a structured framework and developed our research hypothesis. We are going to analyze the data collected from sample customers in Taiwan and generalize the data to the whole population of the country. This research theory will be tested by using a quantitative research method.

\subsection{Procedure}

A total of 263 participants participated in this study. Participants rated a set of three brands for three versions: Apple, Starbuck, and Nike. Each participant rated the extent to which the items described his or her authenticity with the brands listed, the equity of the brands listed, and feelings of satisfaction toward the brands (see Table 1).

Table 1: The profile of sample

\begin{tabular}{|c|c|c|}
\hline Category & Number of respondents & Percentage \\
\hline \multicolumn{3}{|l|}{ Gender } \\
\hline Male & 150 & 60 \\
\hline Female & 113 & 40 \\
\hline \multicolumn{3}{|l|}{ Age } \\
\hline Less than 20 years old & 18 & 7 \\
\hline 20-30 years old & 69 & 26 \\
\hline $30-40$ years old & 60 & 23 \\
\hline $40-50$ years old & 58 & 22 \\
\hline $50-60$ years old & 32 & 12 \\
\hline Above 60 years old & 26 & 10 \\
\hline \multicolumn{3}{|l|}{ Occupation } \\
\hline Student & 102 & 39 \\
\hline Banking/financial/ insurance & 17 & 6 \\
\hline Manufacturing & 40 & 15 \\
\hline Education/ culture & 28 & 11 \\
\hline Government & 6 & 2 \\
\hline Housekeeping & 9 & 3 \\
\hline Media/publishing & 18 & 7 \\
\hline Retail/ distribution & 20 & 8 \\
\hline Medical/hospital/bio-tech & 9 & 4 \\
\hline Others & 14 & 5 \\
\hline \multicolumn{3}{|l|}{ Education } \\
\hline Senior High Diploma or Below & 16 & 6 \\
\hline Associate Bachelor Degree & 59 & 22 \\
\hline Bachelor Degree & 149 & 57 \\
\hline Master Degree & 32 & 12 \\
\hline Ph.D. Degree & 7 & 3 \\
\hline \multicolumn{3}{|l|}{ Monthly income } \\
\hline Less than NT\$ 15,000 & 79 & 30 \\
\hline NT\$ $15,000-24,999$ & 31 & 12 \\
\hline NT\$ $25,000-34,999$ & 46 & 17 \\
\hline NT\$ $35,000-44,999$ & 40 & 15 \\
\hline NT\$ $45,000-54,999$ & 35 & 13 \\
\hline NT\$ 55,000-64,999 & 20 & 8 \\
\hline Over NT\$ 65,000 & 12 & 5 \\
\hline
\end{tabular}




\section{Results}

Following Churchill's (1979) model, the first step in purifying the measurement instrument was to calculate item-to-total correlations and coefficient alpha to eliminate garbage items. In addition, the corrected item-to-total correlations were plotted in descending order, and items with item-to-total correlations below 0.5 . All of these items were found evidently related to their constructs and reliability was evaluated by assessing the internal consistency of the items representing each factor using Cronbach's alpha. The reliability of each factor was as follows: brand authenticity $=0.81$; brand equity $=0.79$ and customer satisfaction $=0.82$. In addition, each of these items had a corrected item-to-total correlation of above 0.50 .

Before estimating the structural equation model based on our conceptual model, we run Confirmatory Factor Analysis (CFA) to examine the discriminant validity of the brand authenticity scale from the brand equity scale and satisfaction scale. The goodness-of-fit for each model was assessed by examining the chi-square statistic, the comparative fit index (CFI), and the root-mean-square error of approximation (RMSEA), NFI, IFI, and CFI, the latter of which needed to be greater than 0.90 (Hair, Black, Babin, Anderson, \& Tatham, 2006). GFI and AGFI index exceed 0.8 . Chi-square/df is smaller than 5 and RMSEA is less than 0.08 (Hair et al., 2006). Additionally, the local fit of the model was assessed by following local fit criteria: indicator reliability greater than 0.30 ; standardized factor loading greater than 0.60 and significant t-value; an average variance explained (AVE) greater than 0.50; and composite reliability greater than 0.60 (Bagozzi \& Yi, 1988).

As shown in Table 2, most of the model-fit indices exceed the respective common acceptance levels suggested by previous research, demonstrating that the measurement model exhibited a good fit with the data collected. Based on the confirmatory factor analysis, all variables were retained. The retained variables will be used in estimating a model via SEM method.

Table 2: Confirmatory factor analysis (CFA) fitting Indices

\begin{tabular}{|c|c|c|c|}
\hline Fitting Indices & $\begin{array}{c}\text { Brand Au } \\
\text { thenticity }\end{array}$ & Brand Equity & $\begin{array}{c}\text { Customer Sati } \\
\text { sfaction }\end{array}$ \\
\hline $\begin{array}{c}\text { CMIN }(\alpha 2 / D F \\
<3\end{array}$ & 2.341 & 2.473 & 2.221 \\
\hline GFI $>0.90$ & 0.904 & 0.949 & 0.983 \\
\hline RMSEA $<0.08$ & 0.072 & 0.075 & 0.68 \\
\hline AGFI $>0.90$ & 0.858 & 0.903 & 0.949 \\
\hline NFI $>0.90$ & 0.917 & 0.940 & 0.972 \\
\hline CFI $>0.90$ & 0.950 & 0.963 & 0.984 \\
\hline
\end{tabular}

Based on the CFA results, we analyzed convergent validity, discriminant validity, and reliability of all the item scales, following the guidelines from previous literature (Fornell \& Larcker, 1981; Gefen \& Straub, 2005). The measurement properties are reported in Table 3 .

Table 3: Reliability and factor loadings

\begin{tabular}{|c|c|c|c|}
\hline Constructs/Measurement Items & Loadings & CR & AVE \\
\hline Brand Authenticity & & 0.95 & 0.583 \\
\hline This brand is inauthentic because of the low labour cost for long working. & 0.767 & & \\
\hline This brand explains the morality and honesty of a particular company. & 0.797 & & \\
\hline This brand needs to note friendly environment. & 0.783 & & \\
\hline This brand includes most functions that are practical in daily usage and authentic value. & 0.692 & & \\
\hline Advertising of this brand sometimes was too exaggerated so that you feel unreal. & 0.667 & & \\
\hline Culture, time, place, and community also make authenticity. & 0.723 & & \\
\hline The authenticity of this brand means reliable & 0.760 & & \\
\hline This brand prefers to be true to them. & 0.752 & & \\
\hline Products of this brand were made genuine and honesty. & 0.805 & & \\
\hline Authenticity of this brand means aesthetic. & 0.672 & & \\
\hline The authenticity is considered as the prestige of this brand. & 0.804 & & \\
\hline This brand is a distinctive image, good word-of- mouth and good quality. & 0.785 & & \\
\hline This brand is authentic because people should have good faith and confidence in their products. & 0.745 & & \\
\hline The authenticity of this brand is very important to consumers. & 0.756 & & \\
\hline The authenticity of this brand fulfills on every possible level. & 0.769 & & \\
\hline I hope everything is original enough. & 0.806 & & \\
\hline
\end{tabular}




\begin{tabular}{|c|c|c|c|}
\hline I 'd like consuming original products. & 0.791 & & \\
\hline Brand equity & & 0.92 & 0.527 \\
\hline The likely quality of this brand is extremely high. & 0.728 & & \\
\hline The likelihood that this brand would be functional is very high. & 0.680 & & \\
\hline This brand would be my first choice. & 0.726 & & \\
\hline I consider myself to be loyal to this brand. & 0.732 & & \\
\hline I will not buy other brands if this brand is available at the store. & 0.760 & & \\
\hline I can recognize this brand among other competing brands. & 0.768 & & \\
\hline I am aware of this brand. & 0.742 & & \\
\hline Some characteristic of this brand comes to my mind quickly. & 0.684 & & \\
\hline I can quickly recall the symbol or logo of this brand. & 0.72 & & \\
\hline I have difficulty imaging this brand in my mind. & 0.70 & & \\
\hline Customer satisfaction & & 0.84 & 0.515 \\
\hline I am satisfied with the brand and its performance. & 0.843 & & \\
\hline If I could do it again, I would buy a brand different from that brand. & 0.654 & & \\
\hline My choice to get this brand has been a wise one. & 0.672 & & \\
\hline I feel bad about my decision to get this brand. & 0.729 & & \\
\hline I am not happy with what I did with this brand. & 0.71 & & \\
\hline
\end{tabular}

Reliability was assessed in terms of composite reliability, which measured the degree to which items are free from random error and therefore yield consistent results. Composite reliabilities in our measurement model ranged from 0.84 to 0.95 Convergent validity was assessed in terms of factor loadings and average variance extracted. According to the prior study, convergent validity requires a factor loading greater than 0.60 and average variance extracted no less than 0.50 . As shown in Table 4, all items had significant factor loadings higher than 0.60 . Average variances extracted ranged from 0.515 to 0.583 , suggesting adequate convergent validity. Thus, all factors in the measurement model had adequate reliability and convergent validity.

Discriminant validity was tested by comparing the average variance extracted (AVE) with the squared correlation between constructs (Fornell \& Larcker, 1981). The AVE was greater than the squared correlation between any pair of constructs, meaning they exhibit discriminant validity (see Table 4).

Table 4: Discriminant validity and correlations among the co nstructs

\begin{tabular}{|c|c|c|c|}
\hline & $\begin{array}{c}\text { Brand Aut } \\
\text { henticity }\end{array}$ & $\begin{array}{c}\text { Brand Eq } \\
\text { uity }\end{array}$ & $\begin{array}{c}\text { Customer Sati } \\
\text { sfaction }\end{array}$ \\
\hline Brand Authenticity & 0.583 & & \\
\hline Brand Equity & $0.759^{* *}$ & 0.527 & \\
\hline $\begin{array}{c}\text { Customer Satisfacti } \\
\text { on }\end{array}$ & $0.754^{* *}$ & $0.713^{* *}$ & 0.515 \\
\hline
\end{tabular}

Notes: $* \mathrm{p}<0.05, * * \mathrm{p}<0.01 ; \mathrm{n}=263$
As the next step, we formulated an SEM using AMOS 20 to analyze our model. The results showed the estimated structural equation model. The estimated model fits the data reasonably well: $(\chi 2 / \mathrm{DF}=1.447$ degrees of freedom, $\mathrm{AGFI}=$ 0.918 , CFI $=0.991$, GFI $=0.949, \mathrm{NFI}=0.970$ and $\mathrm{RMSEA}=$ 0.041 ), all accepted. The model's fit as indicated by these indexes was deemed satisfactory. Thus, we could proceed to examine the path coefficients of the structural model. First, the effect of brand authenticity on brand equity was significant $\left(H 1, \beta=0.948^{* * *}, p<0.001\right)$. Thus, H1 was supported. Second, the effect of brand authenticity on customer satisfaction was significant $\left(\mathrm{H} 2, \beta=0.544^{* * *}\right.$, $\mathrm{p}<0.001$ ), supporting H2. Finally, the effect of brand equity on customer satisfaction was significant $\left(\mathrm{H} 3, \beta=0.469^{* * *}\right.$, $\mathrm{p}<0.001$ ). H3 was also supported (see Figure1).

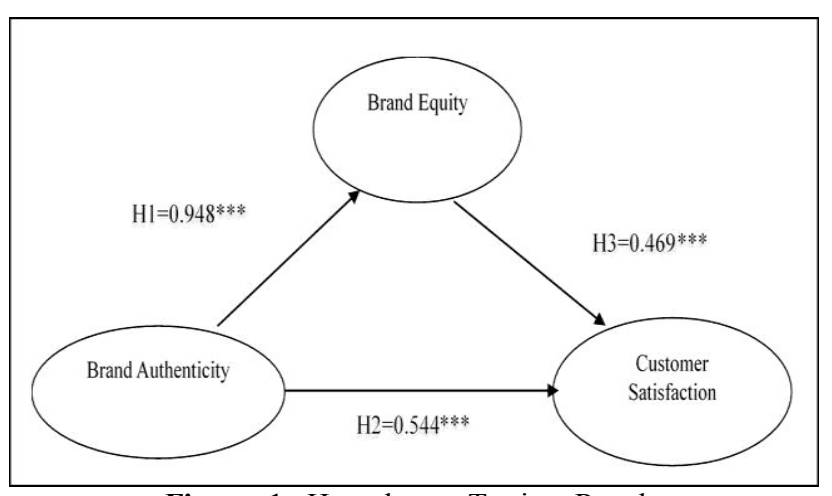

Figure 1. Hypotheses Testing Result. 


\section{Conclusions}

Previous research uses qualitative methods to identified the relationship between goals and authenticating acts (Arnould \& Price, 2008), the relationship between shifting community goals and the nature of brand authenticity (Kates, 2004), and the active information processing strategies employed to find authenticity in the less likely of objects such as reality television (Rose \& Wood, 2005). From previous qualitative research and anecdotal evidence of consumers' quest for authenticity, we know that brand authenticity produces a positive effect on brand attitudes and evaluations. Some consumers authenticate their identity through role performance and communal commitment to the brand (Leigh, Peters, \& Shelton, 2006). This identity formation and identity relationship are essential to brands as consumers form connections and personal relationships with their brands. To this end, Beverland and Farelly (2010) seek to account for what constitutes authenticity by examining how goals underpin assessments of authenticity including the purposive strategies employed by consumers to achieve this assessment.

The results from this study indicated that brand authenticity positively relates to brand equity and customer satisfaction. The results indicate that marketers engage in projects to understand and improve the authenticity their brands provide for their customers, they can use the scale for assessment, planning, and tracking purposes.

\subsection{Managerial Implications}

Products of authenticity brand are better liked, viewed as higher quality, offer greater value and are more likely to be purchased than less authenticity brand. They can command a significant price premium. This means that managers should work to increase perceptions of authenticity for their offerings if this is appropriate for the product or service category. By describing their products as authentic, companies seem to hope to benefit from the effects of authenticity. However, simply labeling or advertising a product may not be sufficient as the consumer may look for signals of the key dimensions of brand authenticity to validate this advertisement. The six dimensions of brand authenticity provide managers with directions for shaping their advertising campaigns so that they are reaping the benefits of authenticity. If a brand is strong in one of these dimensions a firm can utilize that strength and focus on that dimension in its advertising campaign. Consumers will then have information to support the claims of authenticity and can assist in the evaluation of the claims of authenticity that the brand makes.

Moreover, because of lacking the previous empirical research on what brand authenticity is and its effects, the brand authenticity scale was empirically developed (Tran, 2018). Moreover, the six dimensions represent the most comprehensive understanding of brand authenticity. Importantly, brand authenticity has a behavioral impact. It positively relates to customer satisfaction through brand equity. This implies that the basis of a prototypical brand's authenticity cannot be duplicated and is almost absolute. Any imitation of authenticity is likely to lose the essence of the concept. It appears that once a prototypical brand becomes authentic, it will be difficult or impossible for others to compete with it on the same basis. Authenticity appeals for competing brands would need to develop a new and different basis to establish their own authenticity. With my previously discussed theoretical model and empirical studies serving as a backbone, the following section discusses the limitations of this research and proposes possible future research areas to build on these findings.

\subsection{Limitations}

The authors suggest replicating this research using different services and different analytical techniques like structural equation modeling and confirmatory factor analysis. The relative importance of different components of brand authenticity can also be ascertained. Research is also recommended to find out relates to different marketing strategies on brand authenticity.

Based on results from this study, further research should focus on brand authenticity that can lead brand trust for both functional products and experiential products. As authenticity is a way to build brand trust, companies have an incentive to actively highlight their authenticity or take actions to strengthen it. Though building authenticity is not an easy task, and it is difficult to be authentic, brands can benefit from the effects of brand authenticity and gain a critical competitive advantage over their competitors.

Finally, further research should focus on the antecedents and long-term consequence of brand authenticity. In addition, although we have shown the relations of brand authenticity, both directly and indirectly, on short-term consequences, such as satisfaction, the question arises whether brand authenticity affects customer lifetime value (Rust, Zeithaml, \& Lemon, 2000; Vogel, Evanschitzky, \& Ramaseshan, 2008). That is, brand authenticity can build customer loyalty, and how should marketers manage brands to create an authenticity that builds such loyalty.

\section{References}

Aaker, D, A., \& Keller, K.L (1990). Consumer evaluations of brand extensions. Journal of Marketing, 54, 27-41. 
Aaker, D. (1991). Managing brand equity: Capitalizing on the value of a brand name. New York, NY: Free Press.

Ailawadi, K. L., Lehmann, D. R., \& Neslin, S. A. (2003). Revenue premium as an outcome measure of brand equity. Journal of Marketing, 67, 1-17.

Anderson, E. W., \& Sullivan, M. (1993). The antecedents and consequences of customer satisfaction for firms. Marketing of Science, 12, 125-43.

Arnould, E. J., \& Price, L.L. (2000). Authenticating acts and authoritative performances: Questing for self and community. In S. Ratneshwar, D. G. Mick, \& C. Huffman (eds.), The why of consumption: Contemporary perspectives on consumer motives, goals, and desires (pp. 140-163). London, UK: Routledge.

Bagozzi, R. P., \& Yi, Y. (1988). On the evaluation of structural equation models. Journal of the Academy of Marketing Science, 16, 74-94. https://doi.org/10.1007/BF02723327

Bae, J. T., Kim, Y., \& Oh, S. H. (2019). The effects of brand value of oriental medicine cosmetic on purchase intention. Journal of Asian Finance, Economics and Business, 6(2), 105117.https://doi.org/10.13106/jafeb.2019.vol6.no2.105.

Berverland, M. B., \& Farrelly, F. J. (2010). The quest for authenticity in consumption: Consumers' purposive choice of authentic cues to shape experience outcomes. Journal of Consumer Research, 36(50), 838-856.

Beverland, M. B. (2005). Crafting brand authenticity: The case of luxury wines. Journal of Management Studies, 42(5), 1003-29.

Beverland, M. B., \& Luxton, S. (2005). Managing integrated marketing communication (IMC) through strategic decoupling: How luxury wine firms retain brand leadership while appearing to be wedded to the past. Journal of Advertising, 34(4), 103-116.

Blackston, M. (2000). Observations: building brand equity by managing the brand's relationship. Journal of Advertising Research, 40(6), 101-105. https://doi.org/10.2501/JAR-40-6101-105.

Churchill, G. A. (1979). A paradigm for developing better measures of marketing constructs. Journal of Marketing Research, 16(1), 64-73.

Choi, N. H., Wang, J., \& Chen, C. (2019). Brand public benefits and consumer engagement. Journal of Asian Finance, Economics and Business, 6(2), 147-160. https://doi.org/10.13106/jafeb.2019.vol6.no2.147.

Cronbach, L. J. (1951). Coefficient alpha and the internal structure of tests, Psychometrika, 16, 297-334.

Fornell, C., \& Larcker, D. G. (1981). Evaluating structural equation models with unobservable variables and measurement error. Journal of Marketing Research, 18(1), 3950 .

Gefen, D., \& Straub, D. W. (2005): A practical guide to factorial validity Using PLS-Graph: A tutorial and annotated example. Communications of AIS, 16(1), 91-109.

Gilmore, J. H., \& Pine, B. J. (2007). Authenticity: What consumers really want. Boston, MA: Harvard Business School Press.

Grayson, K., \& Martinec, R. (2004). Consumer perceptions of iconicity and indexicality and their influence on assessments of authentic market offerings. Journal of Consumer Research, 31(2), 296-312. https://doi.org/10.1086/422109.

Ha, Y. S. (2018). Online Brand Community and Its Outcomes.
Journal of Asian Finance, Economics and Business, 5(4), $107-$ 116. http://doi.org/10.13106/jafeb.2018.vol5.no4.107.

Hair, J. F. Jr., Black, W. C., Babin, B. J., Anderson, R. E., \& Tatham, R. L. (2006). Multivariate data analysis $\left(6^{\text {th }}\right.$ ed.). Upper Saddle River, NJ: Pearson Prentice Hall.

Hogan, J. E., Lemon, K. N., \& Rust, R. T. (2002). Customer equity management: Charting new directions for the future of marketing. Journal of Service Research, 5(1), 4-12.

Holt, D. B. (2002). Why do brands cause trouble? A dialectical theory of consumer culture and branding. Journal of Consumer Research, 29(1), 70-90.

Hughes, M. (2000). Country music as impression management: A meditation of fabricating authenticity. Poetics, 28(2/3), 185205.

Kasper, H. (1988). On problem perception, dissatisfaction, and brand loyalty. Journal of Economic Psychology 9(9), 387-397.

Kates, S. M. (2004). The Dynamics of brand legitimacy: An interpretive study in the gay men's community. Journal of Consumer Research, 31(9), 455-64.

Keller, K. L., \& Lehmann, D. R. (2006). Brands and branding: research findings and future priorities. Marketing Science, 25(6), 740-759.

Keller, K. L. (1993). Conceptualizing, measuring and managing customer-based brand equity. Journal of Marketing, 57(1), 122.

Kim, H. B., Kim, W., \& An, J. A. (2003). The effect of consumerbased brand equity on firms financial performance. Journal of Consumer Marketing, 20(4), 335- 351.

Lassar, W., Mittal, M., \& Sharma, A (1995). Measuring customerbased brand equity. Journal of Consumer Marketing, 12(4), 11-19.

Leigh, T. W., Peters, C., \& Shelton, J. (2006). The consumer quest for authenticity: The multiplicity of meanings within the MG subculture of consumption. Journal of the Academy of Marketing Science, 34(4), 481-493. https://doi.org/10.1177/0092070306288403.

McShane, L., \& Cunningham, P. (2012). To Thine Own Self Be True? Employees' Judgments of the Authenticity of Their Organization's Corporate Social Responsibility Program. Journal of Business Ethics, 108, 81-100.

Oliver, R. L (1997). Satisfaction: A behavioral perspective on the consumer. New York, NY: McGraw-Hill/Richard D. Irwin.

Pappu, R., \& Quester, P. (2006). Does customer satisfaction lead to improved brand equity? An empirical examination of two categories of retail brands. Journal of Product and Brand Management, 15(1), 4-14.

Rose, R. L., \& Wood, S. (2005). Paradox and the consumption of authenticity through reality television. Journal of Consumer Research, 32(9), 284-296.

Rust, R. T., Zeithaml, V.A., \& Lemon, K. N. (2000). Driving customer equity: How customer lifetime value is reshaping corporate strategy. New York, NY: The Free Press.

Sheldon, K. M., Ryan, R. M., \& Reis, H. R. (1997). What makes for a good day. Competence and autonomy in the day and in the person. Personality and Social Psychology Bulletin, 22, $1270-1279$

Szymanski, D. M., \& Henard, D. H. (2001). Customer satisfaction: A meta-analysis of the empirical evidence. Journal of the Academy Marketing Science, 29(1), 16-35. 
Torres, A., \& Tribó, J. A. (2011). Customer satisfaction and brand equity. Journal of Business Research, 64(10), 1089-1096. https://doi.org/10.1016/j.jbusres.2010.12.001.

Tran, V. D., \& Keng, C. J. (2018). The brand authenticity scale: Development and validation. Contemporary Management Research, 14(4), 277-291. https://doi.org/10.7903/cmr.18581.

Vogel, V., Evanschitzky, H., \& Ramaseshan, B. (2008). Customer equity drivers and future sales. Journal of Marketing, 72(11), 98-108.

Yoo, B., \& Donthu, N. (2001). Developing and validation a multidimensional consumer-based brand equity scale. Journal of Business Research, 52(1), 1-14. https://doi.org/10.1016/S0148-2963(99)00098-3. 